\title{
Isolation of Homoisoflavonoids from the Fibrous Roots of Ophiopogon japonicus by Recycling High-Speed Counter-Current Chromatography and Online Antioxidant Activity Assay
}

\author{
Yifeng Zhou ${ }^{1,3,4}$, Liling Wang ${ }^{2 *}$, Tiebing Liu ${ }^{1,3,4}$, Zedong Mao ${ }^{1}$, Qing Ge $e^{1,3,4}$ and Jianwei Mao ${ }^{1,3,4}$

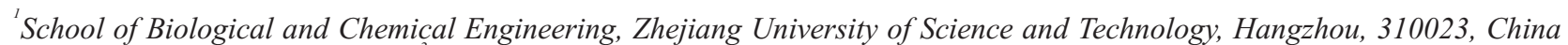 \\ ${ }^{2}$ Zhejiang Academy of Forestry, Hangzhou, 310023, China. \\ ${ }^{3}$ Zhejiang Provincial Key Lab for Chemical and Biological Processing Technology of Farm Produces, Hangzhou, 310023, China \\ ${ }^{4}$ Zhejiang Province Collaborative Innovation Center of Agricultural Biological Resources Biochemical Manufacuring, 310023, China
}

Received: 24 June 2018; accepted: 15 August 2018

\begin{abstract}
Two pairs of homoisoflavonoid analogues, 6-aldehydo-isoophiopogonanone A (1) / 6-aldehydo-isoophiopogonanone B (2) and methylophiopogonanone A (3) / methylophiopogonanone B (4), were obtained from the fibrous roots of Ophiopogon japonicus (L. f.) Ker-Gawl. (FROJ) by silica gel column chromatography (SGCC) and recycling high-speed counter-current chromatography (rHSCCC). First, the ethyl acetate fraction from the $70 \%$ ethanol extract was pre-separated by SGCC with a petroleum ether-ethyl acetate gradient $(50: 1-2: 1, v / v)$. Then, the two sub-fractions containing homoisoflavonoid analogues were further separated by rHSCCC with $n$-hexane-ethyl acetate-methanol-acetonitrile-water $(3: 2: 3.5: 1: 0.5, v / v)$ and $n$-hexane-ethyl acetate-methanol-acetonitrile-water $(3: 2: 2.5: 1: 1.5, v / v)$. Finally, 6-aldehydo-isoophiopogonone A $(16 \mathrm{mg}), 6$-aldehydo-isoophiopogonanone B $(26 \mathrm{mg})$, methylophiopogonanone A (46 mg), and methylophiopogonanone B (148 mg) were obtained with purities of $97.82 \%, 96.70 \%, 97.76 \%$, and $94.62 \%$. Their structures were identified by high-resolution quadrupole-time-of-flight mass spectrometry (HR-QTOF-MS), ultraviolet (UV), and nuclear magnetic resonance spectroscopy $\left({ }^{1} \mathrm{H}-\mathrm{NMR}\right.$ and ${ }^{13} \mathrm{C}$-NMR). These results demonstrated that rHSCCC could be used for the large scale preparation of homoisoflavonoid analogues from FROJ, which provides scientific support for utilization of untraditional medicinal part of $O$. japonicus and also for reduction in waste of plant resources. Additionally, an online antioxidant activity assay was investigated with hyphenated HSCCC-DPPH (1-diphenyl-2-picrylhydrazyl) radical scavenging detection.

Keywords: Ophiopogon japonicus, fibrous roots, homoisoflavonoid analogues, column chromatography, recycling high-speed counter-current chromatography, online antioxidant activity
\end{abstract}

\section{Introduction}

The tuberous roots of Ophiopogon japonicus (L. f.) Ker-Gawl. (known as Maidong) have been used in traditional Chinese medicine to cure acute and chronic inflammation and cardiovascular diseases for thousands of years [1-3]. Moreover, O. japonicus is also considered a functional food in China, Japan, and some south-eastern Asian countries [4]. Homoisoflavonoids, steroidal saponins, and polysaccharides are the main active constituents of $O$. japonicus [4-6], and homoisoflavonoids exhibit various pharmacological activities such as anti-oxidation [7-9], anticancer [10-12], anti-inflammation [2, 13, 14], and cardiovascular protection [15-17]. Usually, the valuable fibrous roots of O. japonicus (FROJ), about $40 \%$ of total roots weight, is discarded when the medicinal part of the tuber roots is collected. Recently, several homoisoflavonoids [7, 10] and steroidal saponins [1, 18-24] have also been purified from FROJ, which could be an important resource for bioactive natural products. Li et al. [25] found that the saponin content in FROJ was higher than that in tubers, and the FROJ can be an important saponin source in this plant. Homoisoflavonoids, a special type of flavonoids containing one additional carbon atom compared to isoflavonoids, show smaller polarity and poorer solubility in methanol or acetonitrile than other flavonoids. Due to the close polarity of homoisoflavonoid analogues, their large scale sepa-

*Author for correspondence: echo22239@163.com. ration is relatively difficult, only by silica gel column chromatography (SGCC) or preparative high-performance liquid chromatography (HPLC).

High-speed counter-current chromatography (HSCCC) is an effective chromatographic separation and preparation technology that is based on continuous liquid-liquid partition [26], which has many advantages such as high load capacity, cheap liquid stationary phase, and low solvent consumption [27]. Recycling high-speed counter-current chromatography (rHSCCC) is one development of elution modes in the recent years [28], has been successfully used for some chiral compounds [29] and natural analogues [30-35], and can improve the separation factor through the cycling the elution in the column. In addition, an online HSCCC-antioxidant activity assay will be a useful technique to screening and preparative isolation of antioxidant components from medical plants. Nevertheless, only Shi et al. [36] has successively used this assay for simultaneous preparative isolation and screening of antioxidants from Selaginella moellendorffii in online coupling way. The method enabled rapid screening of antioxidant components without the need for off-line evaluation of their activity.

In the present study, we developed a new application to obtain two pairs of homoisoflavonoid analogues (Figure 1) by SGCC and rHSCCC from FROJ. This technique provides scientific support for utilization of different parts of the medicinal plant $O$. japonicus, and also for reduction in waste of plant resources. Moreover, an online antioxidant activity was

This is an open-access article distributed under the terms of the Creative Commons Attribution-NonCommercial 4.0 International License (https://creativecommons.org/licenses/by-nc/4.0/), which permits unrestricted use, distribution, and reproduction in any medium for non-commercial purposes, provided the original author and source are credited, a link to the CC License is provided, and changes - if any - are indicated. 
<smiles>Cc1c(O)c(C=O)c(O)c2c1OCC(Cc1ccc3c(c1)OCO3)C2=O</smiles><smiles>COc1ccc(CC2COc3c(C)c(O)c(C=O)c(O)c3C2=O)cc1</smiles><smiles>Cc1c(O)c(C)c2c(c1O)C(=O)C(Cc1ccc3c(c1)OCO3)CO2</smiles><smiles>COc1ccc(CC2COc3c(C)c(O)c(C)c(O)c3C2=O)cc1</smiles>

Figure 1. Chemical structure of homoisoflavonoids from the fibrous roots of O. japonicus

investigated with hyphenated HSCCC-DPPH (1-diphenyl-2picrylhydrazyl) radical scavenging detection.

\section{Experimental}

2.1. Apparatus. Ultrasonic-assisted extraction was carried out using a digitally controlled ultrasonic bath (KQ-300DE, Kunshan Ultrasonic Instruments Co. Ltd., China). The HSCCC systems were comprised of a TBE-300A module, a TBP5002 constant-flow pump, and a ultraviolet (UV) monitor (Tauto Biotechnique Company, Shanghai, China). The TBE-300A module was equipped with 3 polytetrafluoroethylene preparative coils (2.6 mm, i.d.; total volume, $300 \mathrm{~mL}$ ) and a $20-\mathrm{mL}$ sample injection loop, and the revolution speed could be adjusted in the range from 0 to $1000 \mathrm{rpm}$. A constant temperature regulator (HX-105, Beijing Changliu Science Implement, China) was used to control the temperature of the separation coils. HPLC was performed on a Shimadzu LC-20AD separations module connected to a SIL-20A auto sampler, a CTO-20A column oven, and a SPD-20A UV/visible detector (Shimadzu Corporation, Japan). The mass spectroscopy (MS) analyses were applied on an AB SCIEX Q-TOF 4600 mass spectrometer (SCIEX Corporation, USA) in the negative mode according to a previous study [5]. The nuclear magnetic resonance (NMR) spectra were determined by a Bruker Avance 400 NMR spectrometer (Bruker Corporation, Germany). The UV spectra were analyzed with a UV-2600 spectrophotometer (Shimadzu Corporation, Japan).

2.2. Reagents and Materials. The HPLC-grade acetonitrile was obtained from the TEDIA Company, Inc. (Fairfield, OH, USA). DPPH (97\%) was purchased from TCI (Shanghai) Development Co., Ltd., for antioxidant activity experiments. The other solvents utilized for the separation and purification of the FROJ were all of analytical grade and were bought from Shanghai Lingfeng Chemical Reagent Co. Ltd., China. The pure water used in this study was produced by a DirectQ3 water system (Millipore, Bedford, MA, USA). The chromatographic silica gel and TLC plate were purchased from Qingdao Ocean Chemical Factory (Qingdao, China). The FROJ was collected in 2014 from Shengshan Town, Cixi City (Zhejiang province, China) and was authenticated by Professor Jianwei Mao (Zhejiang University of Science and Technology, Hangzhou, China). The voucher specimens (No.201405) were deposited in Zhejiang Provincial Key Laboratory for Chemical and Biological Processing Technology of Farm Product, Zhejiang University of Science and Technology, Hangzhou, China.

2.3. Preparation of the Crude Extract. The dried FROJ (1 kg, $60 \mathrm{mesh})$ were ultrasonic-assisted extracted two times with 10-fold amounts of $70 \%$ ethanol. The extracts was immediately concentrated, and a brown syrup (448 g) was obtained. Then, the syrup was suspended in water and successively extracted using petroleum ether, ethyl acetate, and $n$-butanol. The ethyl acetate layer was concentrated to dryness in a rotary evaporator, and the dried ethyl acetate extract $(9 \mathrm{~g})$ was obtained and stored at $4{ }^{\circ} \mathrm{C}$ prior to separation.

2.4. Pre-Separation of the Crude Extract by SGCC. The silica gel (200 g, 200-300 mesh) was suspended in petroleum ether $\left(500 \mathrm{~mL}, 60-90{ }^{\circ} \mathrm{C}\right)$, and then transferred to a glass column $(80 \mathrm{~cm}$ length $\times 5 \mathrm{~cm}$ i.d.). The ethyl acetate fraction from the FROJ $(8 \mathrm{~g})$ was first dissolved in ethyl acetate $(30 \mathrm{~mL})$ and mixed with silica gel $(10 \mathrm{~g})$. Then, this dry sample was subjected to the silica column after ethyl acetate was removed on a water bath at $50{ }^{\circ} \mathrm{C}$. Secondly, the SGCC was eluted with petroleum ether (60-90 $\left.{ }^{\circ} \mathrm{C}\right)$-ethyl acetate gradient $(50: 1,20: 1,10: 1,5: 1$, and 2:1, $v / v$ ). Eluents of $100 \mathrm{~mL}$ each were analyzed on GF254 TLC plates at room temperature, using petroleum ether-ethyl acetate $(4: 1, v / v)$ as the developing reagent. Spots were visualized under an ultraviolet lamp at $254 \mathrm{~nm}$ and $5 \%$ $\mathrm{FeCl}_{3}-\mathrm{EtOH}(v / v)$ color development reagent. The eluates containing similar spots were merged into one sub-fraction and concentrated in the rotary evaporator. The target subfraction containing the two pairs of homoisoflavonoid analogues was stored in a desiccator for the subsequent rHSCCC separation.

\subsection{Further Separation by rHSCCC}

2.5.1. Measurement of the Partition Coefficient (K). The selected two-phase solvent systems were prepared and equilibrated for the investigation of the partition coefficient. Two milliliters of each phase were transferred into a $10-\mathrm{mL}$ test tube, in which $1 \mathrm{mg}$ of the target sub-fraction from SGCC was placed in beforehand. When the two phases were thoroughly equilibrated after shaking vigorously, $1 \mathrm{~mL}$ solution taken from each phase was filtrated through a $0.45-\mu \mathrm{m}$ membrane and analysed by HPLC. The $K$ value was defined as the ratio of the peak area in the upper phase and the lower phase of a given compound. The separation factor $(\alpha)$ was calculated using the ratio of $K$ values of two homoisoflavonoid analogues.

2.5.2. Preparation of HSCCC Solvent System and Sample Solution. The two-phase solvent system finally applied for rHSCCC was composed of $n$-hexane-ethyl acetate-methanolacetonitrile-water (HEAMW, 3:2:3.5:1:0.5, v/v) and HEAMW $(3: 2: 2.5: 1: 1.5, v / v)$, respectively. The upper phase (stationary phase) and the lower phase (mobile phase) were separated in a separation funnel and degassed by ultrasonication for 
$30 \mathrm{~min}$ shortly prior to use. Sample solutions of sub-fraction $7(49 \mathrm{mg})$ and sub-fraction $8(257 \mathrm{mg})$ from SGCC for rHSCCC separation were prepared by dissolving the sample in a $10-\mathrm{mL}$ solvent mixture of both phases, respectively.

2.5.3. rHSCCC Separation Procedure. Because homoisoflavonoid analogues have similar $K$ values, the classical elution mode of CCC cannot achieve satisfactory resolution. The rHSCCC was carried out by connecting the outlet of the detector to the inlet of the pump. The experimental process was performed as follows. First, the HSCCC column was filled up with the upper stationary phase of the solvent system at $20 \mathrm{~mL} / \mathrm{min}$. Then, the lower mobile phase was pumped into it at $2.0 \mathrm{~mL} / \mathrm{min}$ when the column rotated speed reached $900 \mathrm{rpm}$. Second, the sample solution was injected into the column after the hydrodynamic equilibrated. Third, the recycling elution mode was performed by channeling the outlet of the detector to the inlet of the pump with a pipeline shortly before the first cycle elution started. When the target sample was separated after two HSCCC cycles, the recycling elution was stopped by disconnecting the pipeline to conventional HSCCC. Finally, the target compounds were collected manually according to the chromatograms at a wavelength of $285 \mathrm{~nm}$.

2.6. HPLC Analysis. The HPLC method was used to analyze the homoisoflavonoids from the fibrous roots isolated by SGCC and HSCCC after some modifications [35]. The separation was performed on a Shimadzu C18 column $(5 \mu \mathrm{m}$, $250 \mathrm{~mm} \times 4.6 \mathrm{~mm}$ ). The volume ratio of mobile solvents A (water) and B (acetonitrile) was kept at 35:65, and the temperature was set at $30{ }^{\circ} \mathrm{C}$. The flow rate of the mobile phase was $1 \mathrm{~mL} / \mathrm{min}$. The detection wavelength was monitored at $285 \mathrm{~nm}$.

2.7. Online Antioxidant Activity Assay. An online detection of antioxidant activity for sub-fraction 8 in the ethyl acetate extract of FROJ was developed by combining HSCCC with online radical scavenging using DPPH as the model radical. The HSCCC system conditions were the same as the previous separation procedure, and the post-column effluent from HSCCC was mixed with the DPPH reagent

(A)

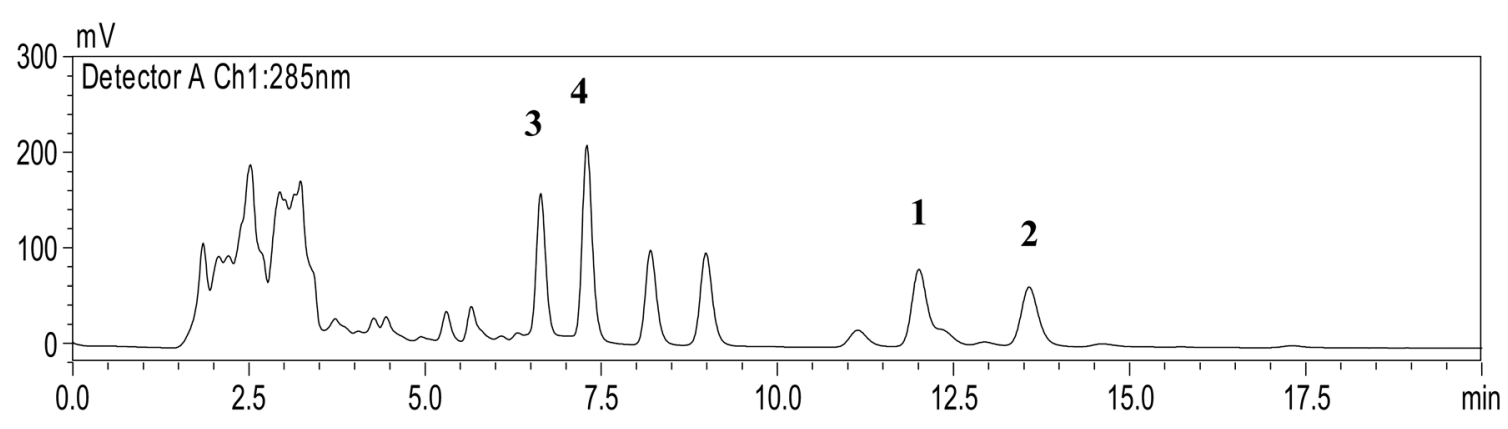

(B)

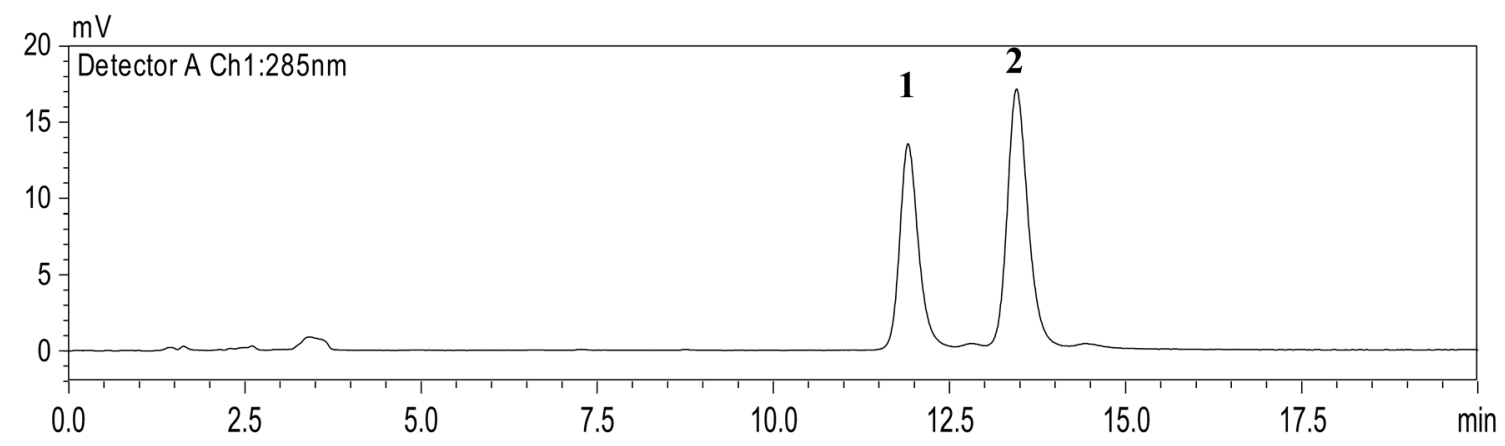

(C)

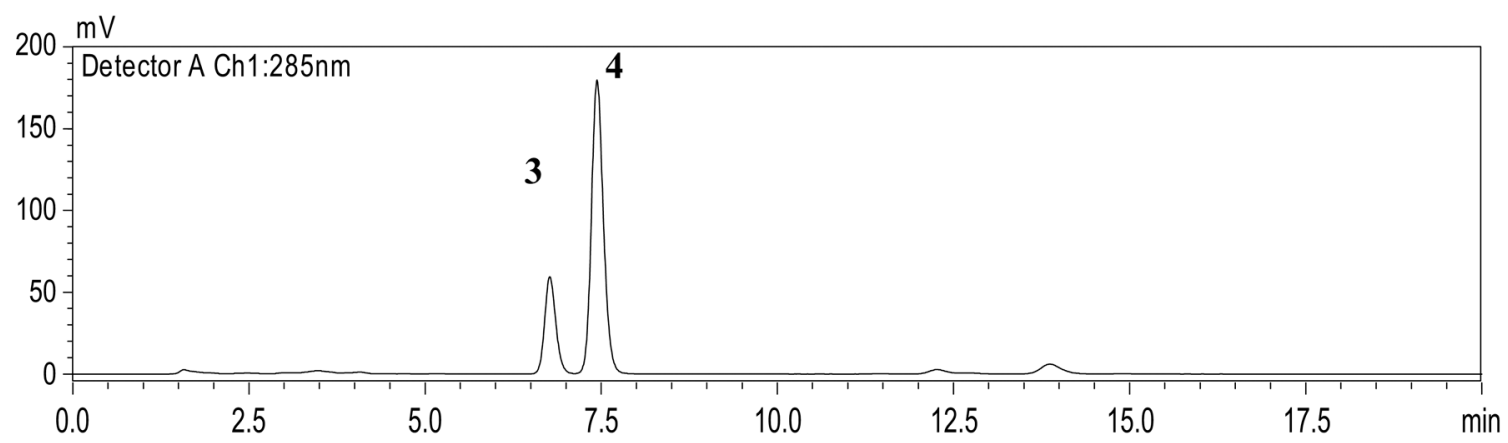

Figure 2. HPLC chromatograms of different fractions from the fibrous roots of $O$. japonicus: (A) the ethyl acetate fraction, (B) sub-fraction 7 from ethyl acetate fraction by SGCC, and (C) sub-fraction 8 from ethyl acetate fraction by SGCC. HPLC conditions: Shimadzu C18 column $(5 \mu \mathrm{m}, 250 \mathrm{~mm} \times 4.6 \mathrm{~mm})$; temperature $=30{ }^{\circ} \mathrm{C}$; mobile phase: water and acetonitrile $(35: 65, v / v)$; flow rate $=1 \mathrm{~mL} / \mathrm{min}$; detection wavelength $=$ 285 nm. Peaks: 1 = 6-aldehydo-isoophiopogonanone A; 2 =6-aldehydo-isoophiopogonanone B; $3=$ methylophiopogonanone A; 4 = methylophiopogonanone $\mathrm{B}$ 
using a Shimadzu LC-20AD pump module and a SPD-20A UV/visible detector. The sample $(50 \mathrm{mg})$ was injected into HSCCC system and detected at $285 \mathrm{~nm}$. The HSCCCseparated components reacted post-column with DPPH at a concentration of $50 \mu \mathrm{mol} / \mathrm{L}$ in methanol. The flow of the reagent solution was set to $1 \mathrm{~mL} / \mathrm{min}$. The online antioxidant activity assay was detected at a variable wavelength of $517 \mathrm{~nm}$ as a negative peak. The length of the tube used for the post-column reaction was $9 \mathrm{~m}$ to achieve a sufficient reaction time.

\section{Results and Discussion}

3.1. Pre-Separation by SGCC. As shown in Figure 2A, 6 obvious chromatographic peaks can be found from $6 \mathrm{~min}$ to $15 \mathrm{~min}$ in the ethyl acetate fraction. After eluting with a petroleum ether $\left(60-90{ }^{\circ} \mathrm{C}\right)$-ethyl acetate gradient by SGCC, the ethyl acetate fraction $(8 \mathrm{~g})$ was pooled to $20 \mathrm{sub}$-fractions (sub-fraction 1-20) according to their TLC profiles. Subfraction $7(312 \mathrm{mg})$ and sub-fraction $8(494 \mathrm{mg})$ with the same single TLC spot have two pairs of homoisoflavonoid analogues and were further verified by HPLC (Figures 2B and $\mathrm{C}$ ). However, the poor solubility in methanol or acetonitrile of these homoisoflavonoid analogues could not be isolated on preparative HPLC. Due to the failure to separate the two pairs of homoisoflavonoid analogues by preparative HPLC and repeat SGCC, HSCCC was tried in our further experiment.

3.2. Selection of Two-Phase Solvent System. The most important step for successful separation by HSCCC is finding a suitable two-phase solvent system. In view of the solubility and polarities of the target compounds, the combination of hexane-ethyl acetate-methanol-water (HEMW) was chosen as the initial biphasic system according the Ito's work [26], starting with $n$-hexane-ethyl acetate-methanol-water (HAMW, 4:5:4:5 to 10:0:5:5, v/v) with increasing order of hydrophobicity of their organic phases. As shown by No. 1 to 6 in Table 1, the four homoisoflavonoids tended to dissolve well into the organic phase with high $K$ values. Therefore, the volume ratios of $n$-hexane versus ethyl acetate and methanol versus water were adjusted to change $K$ values. When $n$-hexane versus ethyl acetate was fixed at 3:2, the $K$ values were largely reduced with increasing proportion of methanol (Table 1, No. 7-9). When $n$-hexane versus ethyl acetate was changed to $2: 3$, the $K$ values of four compounds could be between 0.5 and 2 (Table 1, No. 10-12). However, the values $\alpha_{12}$ and $\alpha_{34}$ were $<1.5$. According to the reference of HSCCC [37], acetonitrile is added into the volume ratio of $n$-hexane versus ethyl acetate at $2: 3 ; \alpha_{12}$ and $\alpha_{34}$ increased to approximately 1.2 , with acceptable $K$ values from 0.5 to 1 for rHSCCC (see Table 2). Thus, the solvent systems of

Table 1 The $K$ and $\alpha$ values of 4 compounds in HEMW ${ }^{a}$ systems

\begin{tabular}{|c|c|c|c|c|c|c|c|}
\hline No. & Solvent ratio & $K_{1}$ & $K_{2}$ & $\alpha_{12}$ & $K_{3}$ & $K_{4}$ & $\alpha_{34}$ \\
\hline 1 & $4: 5: 4: 5$ & - & - & - & 45.9 & 49.3 & 1.07 \\
\hline 2 & $5: 5: 5: 5$ & - & - & - & 20.6 & 21.1 & 1.02 \\
\hline 3 & $6: 4: 5: 5$ & - & - & - & 17.6 & 18.5 & 1.05 \\
\hline 4 & $7: 3: 5: 5$ & - & - & - & 16.1 & 17.3 & 1.07 \\
\hline 5 & $8: 2: 5: 5$ & - & - & - & 12.9 & 14.4 & 1.11 \\
\hline 6 & $10: 0: 5: 5$ & 71.7 & 54.4 & 0.75 & 12.7 & 14.5 & 1.14 \\
\hline 7 & $3: 2: 3: 2$ & 17.7 & 20.7 & 1.17 & 4.29 & 4.53 & 1.06 \\
\hline 8 & $3: 2: 3.5: 1.5$ & 6.24 & 7.50 & 1.20 & 1.44 & 1.62 & 1.12 \\
\hline 9 & $3: 2: 4: 1$ & 2.30 & 2.70 & 1.17 & 0.60 & 0.66 & 1.10 \\
\hline 10 & $2: 3: 3: 2$ & 4.53 & 4.88 & 1.08 & 1.78 & 1.85 & 1.04 \\
\hline 11 & $2: 3: 3.5: 1.5$ & 3.66 & 4.01 & 1.10 & 1.50 & 1.57 & 1.05 \\
\hline 12 & $2: 3: 4: 1$ & 1.59 & 1.75 & 1.10 & 0.59 & 0.63 & 1.08 \\
\hline
\end{tabular}

HEAMW at $3: 2: 3.5: 1: 0.5$ and $3: 2: 2.5: 1: 1.5$ were selected for subsequent HSCCC separation.

3.3. rHSCCC Separation and HPLC Identification. rHSCCC is a useful methodology to improve the chromatographic resolution among compounds with similar partition coefficients, which is extremely suitable for the separation of analogues. The resolution of analogues will increase after each cycle, but the solvent consumption remains the same. As shown in Figures $3 \mathrm{~A}$ and B, the two peaks overlapped seriously in the first cycle; nevertheless, the second separation cycle exhibits a better separation; thus, the rHSCCC was returned to normal elution. Finally, the two pairs of peaks with 4 compounds were well separated and collected in the third cycle. The retention ratios of the organic stationary phase for the two rHSCCC were approximately $55 \%$ and $58 \%$, which were calculated from the volume of the stationary phase collected from the column after the separation was completed. As shown in Figure 4, compound 1 (16 mg), 2 (26 mg), 3 (46 mg), and 4 (148 mg) were obtained with purity of $97.82 \%, 96.70 \%, 97.76 \%$ and $94.62 \%$, respectively, after the recovery of organic solvents.

3.4. Structural Identification of Isolated Compounds. Compounds 1-4 were purified as colorless needle crystals. The structural illustration of 4 compounds from the FROJ was carried out by UV and QTOF-MS (shown in Table 3), and NMR spectra were listed as follows.

Compound 1: ${ }^{1} \mathrm{H}-\mathrm{NMR}\left(\mathrm{CDCl}_{3}, 400 \mathrm{MHz}\right): \delta 4.26(1 \mathrm{H}, \mathrm{dd}$, $J=8,12 \mathrm{~Hz}, \mathrm{H}-2), 4.45(1 \mathrm{H}, \mathrm{dd}, J=4,16 \mathrm{~Hz}, \mathrm{H}-2)$, 2.88-2.92 (1H, m, H-3), $12.97(1 \mathrm{H}, \mathrm{s}, 5-\mathrm{OH}), 10.01(1 \mathrm{H}, \mathrm{s}$, 6-CHO), $12.92(1 \mathrm{H}, \mathrm{s}, 7-\mathrm{OH}), 2.00\left(3 \mathrm{H}, \mathrm{s}, 8-\mathrm{CH}_{3}\right), 2.70(1 \mathrm{H}$, $\mathrm{dd}, J=8,12 \mathrm{~Hz}, \mathrm{H}-9), 3.20(1 \mathrm{H}, \mathrm{dd}, J=4,16 \mathrm{~Hz}, \mathrm{H}-9)$, 6.65-6.78 (3H, m, H-2', H-5',H-6'), 5.94 (2H, s, -O- $\mathrm{CH}_{2}-\mathrm{O}-$-); ${ }^{13} \mathrm{C}-\mathrm{NMR}\left(\mathrm{CDCl}_{3}, 400 \mathrm{MHz}\right): \delta 197.20$ (C-4), 191.12 (CHO6), 168.28 (C-10), 167.17 (C-5), 164.80 (C-7), 148.05 (C-4'), 146.63 (C-3'), 130.87 (C-1'), 122.13 (C-6'), 109.42 (C-2'), 108.52 (C-5'), 105.48 (C-11), 103.77 (C-6), $101.11\left(-\mathrm{O}-\mathrm{CH}_{2}-\mathrm{O}-\right)$, 100.74 (C-8), 69.98 (C-2), 46.27 (C-3), 32.40 (C-9), 5.99 $\left(\mathrm{CH}_{3}-8\right)$.

Compound 2: ${ }^{1} \mathrm{H}-\mathrm{NMR}\left(\mathrm{CDCl}_{3}, 400 \mathrm{MHz}\right): \delta 4.26(1 \mathrm{H}, \mathrm{dd}$, $J=8,12 \mathrm{~Hz}, \mathrm{H}-2), 4.45(1 \mathrm{H}, \mathrm{dd}, J=4,16 \mathrm{~Hz}, \mathrm{H}-2)$, 2.88-2.92 (1H, m, H-3), $12.97(1 \mathrm{H}, \mathrm{s}, 5-\mathrm{OH}), 10.01(1 \mathrm{H}, \mathrm{s}$, 6-CHO), $12.92(1 \mathrm{H}, \mathrm{s}, 7-\mathrm{OH}), 2.00\left(3 \mathrm{H}, \mathrm{s}, 8-\mathrm{CH}_{3}\right), 2.72(1 \mathrm{H}$, $\mathrm{dd}, J=8,12 \mathrm{~Hz}, \mathrm{H}-9), 3.22(1 \mathrm{H}, \mathrm{dd}, J=4,16 \mathrm{~Hz}, \mathrm{H}-9), 7.14$ (2H, d, $J=8 \mathrm{~Hz}, \mathrm{H}-2^{\prime}, \mathrm{H}-6$ '), 6.88 (2H, d, $J=8 \mathrm{~Hz}, \mathrm{H}-3$ ', H-5'), 3.81 (3H, s, 4'-OCH $)$; ${ }^{13} \mathrm{C}-\mathrm{NMR}\left(\mathrm{CDCl}_{3}, 400 \mathrm{MHz}\right)$ : $\delta 197.55$ (C-4), 191.28 (CHO-6), 168.43 (C-10), 167.37 (C-5), 164.97 (C-7), 158.82 (C-4'), 130.21 (C-2', C-6'), 129.31 (C-1'), 114.43 (C-3', C-5'), 105.62 (C-11), 103.93 (C-6), 100.92 (C-8), 70.16 (C-2), $55.46\left(4^{\prime}-\mathrm{OCH}_{3}\right), 46.27$ (C-3), 32.02 (C-9), $6.14\left(\mathrm{CH}_{3}-8\right)$.

Compound 3: ${ }^{1} \mathrm{H}-\mathrm{NMR}\left(\mathrm{CDCl}_{3}, 400 \mathrm{MHz}\right): \delta 4.12(1 \mathrm{H}, \mathrm{dd}$, $J=8,12 \mathrm{~Hz}, \mathrm{H}-2), 4.29(1 \mathrm{H}, \mathrm{dd}, J=4,12 \mathrm{~Hz}, \mathrm{H}-2)$, 2.77-2.82 (1H, m, H-3), $12.38(1 \mathrm{H}, \mathrm{s}, 5-\mathrm{OH}), 5.37(1 \mathrm{H}, \mathrm{s}$, 7-OH), 2.70 (1H, dd, $J=4,12 \mathrm{~Hz}, \mathrm{H}-9), 3.16(1 \mathrm{H}, \mathrm{dd}, J=8$, $12 \mathrm{~Hz}, \mathrm{H}-9)$, 6.67-6.77 (3H, m, H-2', H-5',H-6'), 5.94 (2H, s, $\left.-\mathrm{O}-\mathrm{CH}_{2}-\mathrm{O}-\right), 2.03\left(3 \mathrm{H}, \mathrm{s}, 6-\mathrm{CH}_{3}\right), 2.07\left(3 \mathrm{H}, \mathrm{s}, 8-\mathrm{CH}_{3}\right)$; ${ }^{13} \mathrm{C}-\mathrm{NMR}\left(\mathrm{CDCl}_{3}, 400 \mathrm{MHz}\right): \delta 198.43$ (C-4), 160.79 (C-5), 159.76 (C-10), 157.89 (C-7), 148.02 (C-3'), 146.50 (C-4'), 131.93 (C-1'), 122.30 (C-6'), 109.55 (C-2'), 108.53 (C-5'), 102.95 (C-6),

Table 2 The $K$ and $\alpha$ values of four compounds in HEMAW ${ }^{a}$ systems

\begin{tabular}{lccccccc}
\hline No. & Solvent ratio & $K_{1}$ & $K_{2}$ & $\alpha_{12}$ & $K_{3}$ & $K_{4}$ & $\alpha_{34}$ \\
\hline 1 & $3: 2: 2: 1: 2$ & 9.56 & 12.4 & 1.30 & 2.55 & 2.88 & 1.13 \\
2 & $3: 2: 2.5: 1: 1.5$ & 3.29 & 4.14 & 1.26 & 0.81 & 0.94 & 1.16 \\
3 & $3: 2: 3: 1: 1$ & 1.47 & 1.79 & 1.22 & 0.37 & 0.43 & 1.16 \\
4 & $3: 2: 3.5: 1: 0.5$ & 0.59 & 0.68 & 1.15 & 0.21 & 0.25 & 1.16 \\
\multicolumn{7}{c}{ Hexane-ethyl acetate-methanol-acetonitrile-water. } \\
\end{tabular}


(A)

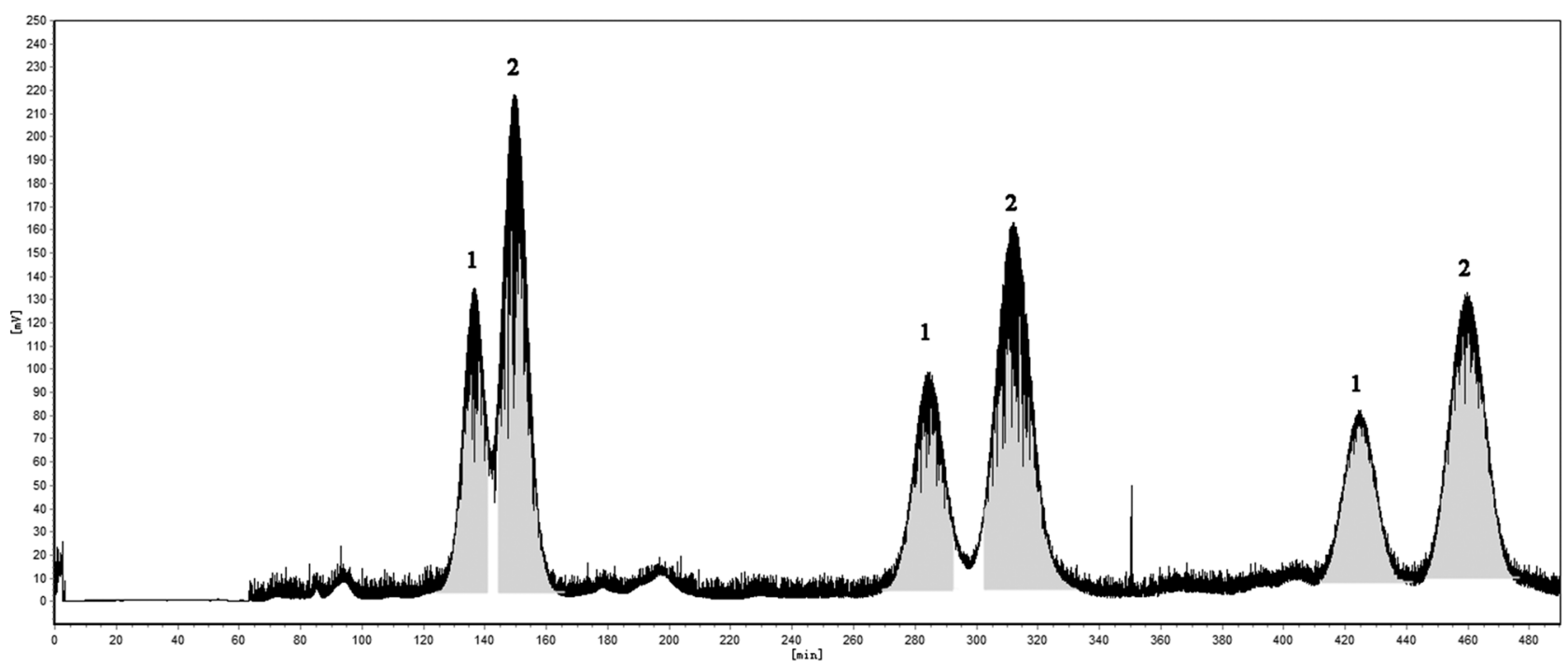

(B)

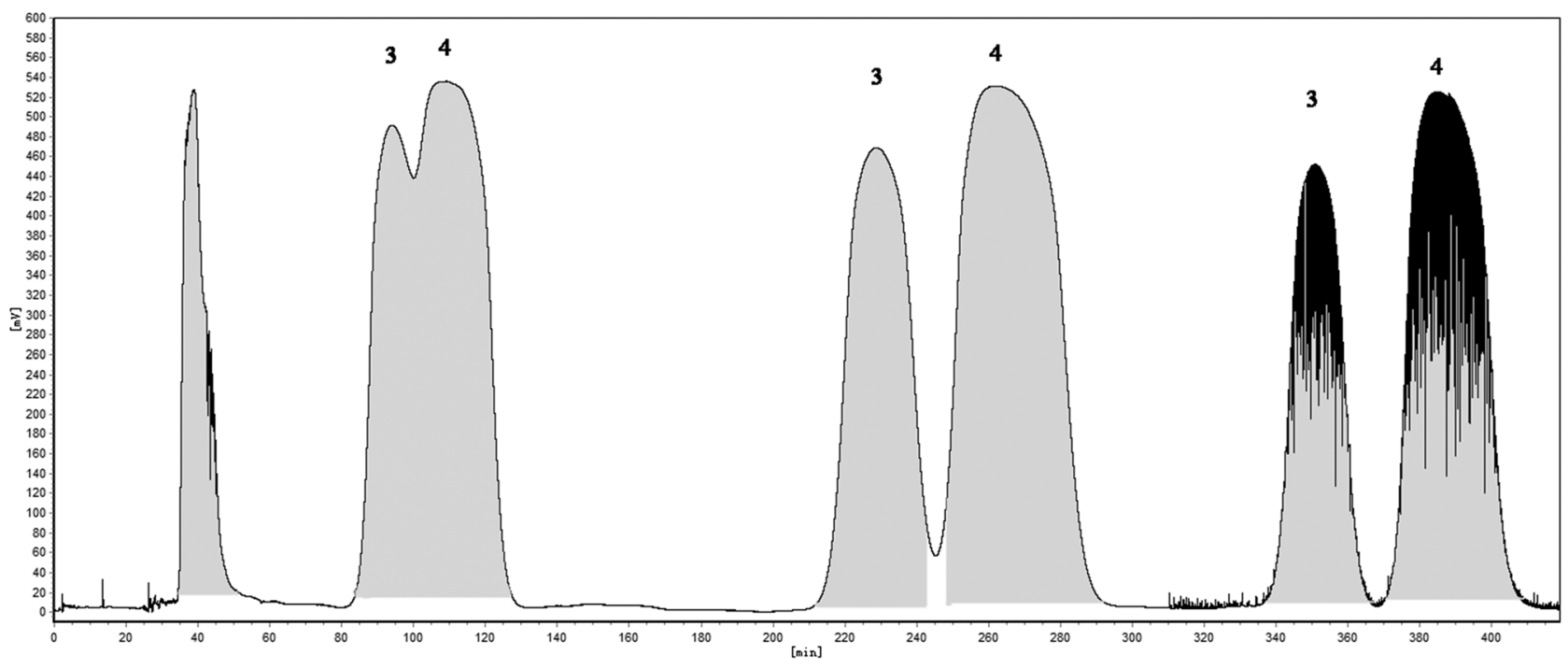

Figure 3. The recycling HSCCC chromatograms of different fractions from the fibrous roots of $O$. japonicus: (A) sub-fraction 7 from ethyl acetate fraction by SGCC and (B) sub-fraction 8 from ethyl acetate fraction by SGCC. Peaks: 1 = 6-aldehydo-isoophiopogonanone A; $2=6$-aldehydo-isoophiopogonanone B; 3 = methylophiopogonanone A; 4 = methylophiopogonanone B. HSCCC conditions: revolution $=900 \mathrm{rpm}$; flow rate $=$ $2 \mathrm{~mL} / \mathrm{min}$; temperature $=25^{\circ} \mathrm{C}$; detection wavelength $=285 \mathrm{~nm}$; upper phase for stationary phase and lower phase for mobile phase; solvent system: HEAMW $(3: 2: 3.5: 1: 0.5, v / v)$ for $(\mathrm{A})$ and HEAMW $(3: 2: 2.5: 1: 1.5, v / v)$ for $(\mathrm{B})$

102.43 (C-8), 101.67 (C-11), $101.13\left(-\mathrm{O}-\mathrm{CH}_{2}-\mathrm{O}-\right), 69.03$ (C-2), 46.94 (C-3), 32.74 (C-9), $7.49\left(\mathrm{CH}_{3}-8\right), 7.00\left(\mathrm{CH}_{3}-6\right)$.

Compound 4: ${ }^{1} \mathrm{H}-\mathrm{NMR}\left(\mathrm{CDCl}_{3}, 400 \mathrm{MHz}\right): 84.12(1 \mathrm{H}, \mathrm{dd}$, $J=8,12 \mathrm{~Hz}, \mathrm{H}-2), 4.29(1 \mathrm{H}, \mathrm{dd}, J=4,12 \mathrm{~Hz}, \mathrm{H}-2), 2.77-$ $2.83(1 \mathrm{H}, \mathrm{m}, \mathrm{H}-3), 12.38(1 \mathrm{H}, \mathrm{s}, 5-\mathrm{OH}), 5.41(1 \mathrm{H}, \mathrm{s}, 7-\mathrm{OH})$, $2.66(1 \mathrm{H}, \mathrm{m}, \mathrm{H}-9), 3.18$ (1H, dd, $J=4,12 \mathrm{~Hz}, \mathrm{H}-9), 7.15$ (2H,d, $J=8 \mathrm{~Hz}, \mathrm{H}-2$ ', H-6'), 6.86 (2H, d, $J=8 \mathrm{~Hz}, \mathrm{H}-3$ ',H5'), $3.80\left(3 \mathrm{H}, \mathrm{s}, 4\right.$ '- $\left.\mathrm{OCH}_{3}\right), 2.03\left(3 \mathrm{H}, \mathrm{s}, 6-\mathrm{CH}_{3}\right), 2.07(3 \mathrm{H}, \mathrm{s}$, 8-CH3); ${ }^{13} \mathrm{C}-\mathrm{NMR}\left(\mathrm{CDCl}_{3}, 400 \mathrm{MHz}\right): \delta 198.64$ (C-4), 160.40 (C-5), 159.75 (C-10), 157.91 (C-7), 130.21 (C-1'), 130.26 (C- 2', C-6'), 114.24 (C-3', C-5'), 102.95 (C-6), 102.43 (C-8), 101.67 (C-11), 69.05 (C-2), $55.44\left(4^{\prime}-\mathrm{OCH}_{3}\right)$, 46.99 (C-3), 32.13 (C-9), $7.49\left(\mathrm{CH}_{3}-8\right), 7.00\left(\mathrm{CH}_{3}-6\right)$.

Compared with the NMR data given in previous literature studies, the results of compounds 1-2 were consistent with those of components I and II in the work of Kaneda et al. [38]; compounds 3-4 can be identified as methylophiopogonanone A (3) and methylophiopogonanone B (4) [39]. For convenience, compounds 1 and 2 were named 6-aldehydoisoophiopogonone A (1) and 6-aldehydo-isoophiopogonanone
B (2), according to the chemical structures and previous reports [4-6, 38-40]. In previous studies, the two analogues could be achieved through SGCC with benzene as the developing reagent $[38,40]$ or slow flow LH-20 with ethanol as the elute solvent $[39,40]$, which is not suitable for large scale purification.

3.5. Online HSCCC-DPPH Antioxidant Activity. A schematic diagram of the instrumentation is given in Figure 5. The homoisoflavonoid analogues of methylophiopogonanone A (3) and methylophiopogonanone B (4) obtained from subfraction $8(50 \mathrm{mg})$ in ethyl acetate extract of FROJ were first isolated by HSCCC using HEAMW (3:2:2.5:1:1.5, v/v) (Figure 6A). Before the antioxidant activity detection, the effluent reacted with DPPH solution in a $9 \mathrm{~m}$ pressure equalization (PE) tube; nearly 5-min delay was investigated in the chromatogram of DPPH radical scavenging activity (Figure 6B). These results revealed that methylophiopogonanone A (3) and methylophiopogonanone B (4) isolated from subfraction 8 in ethyl acetate extract of FROJ had inhibitory activity in the scavenging of DPPH radicals. The offline 

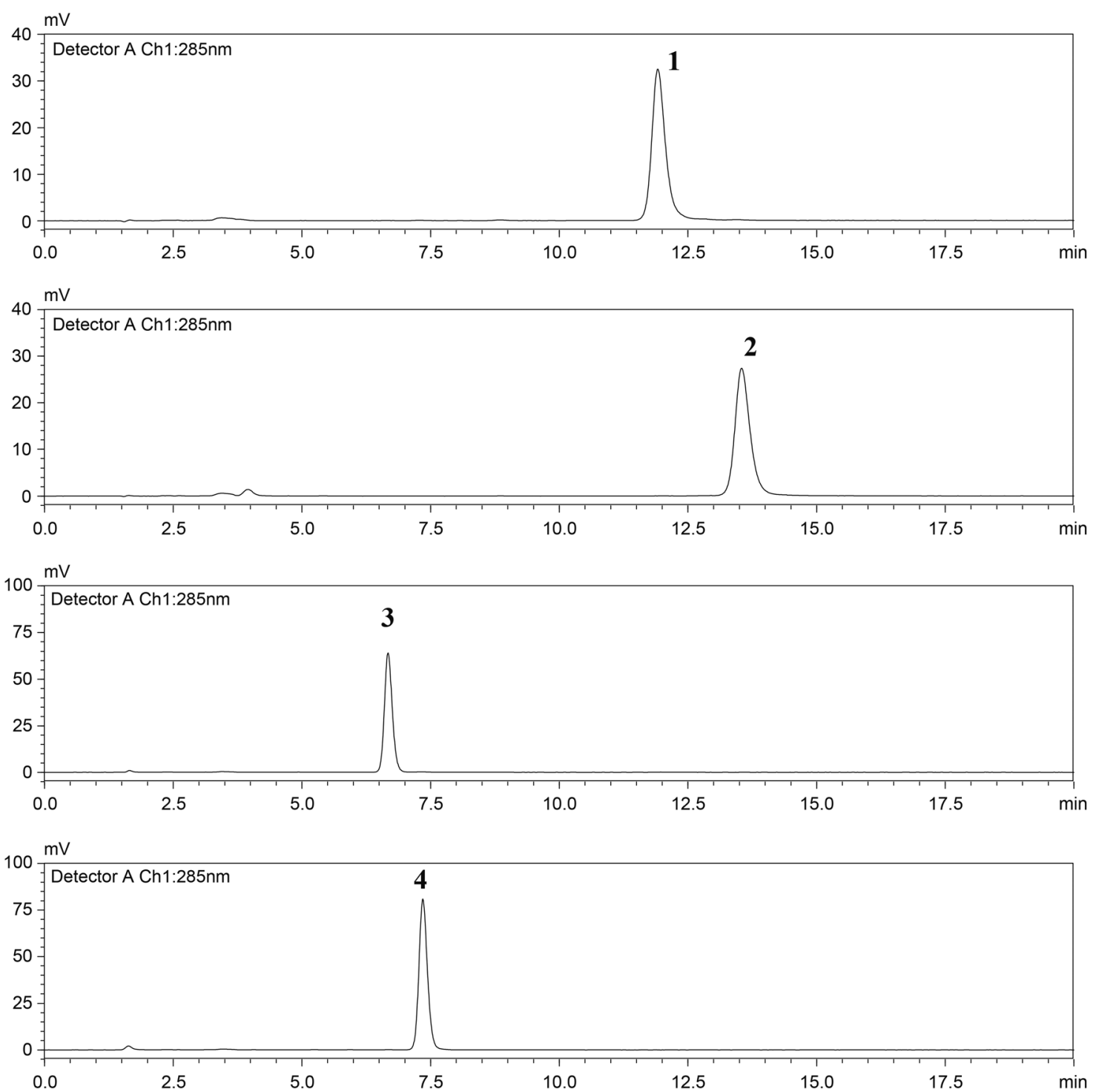

Figure 4. HPLC chromatograms of the isolated peak fractions by HSCCC. Peaks: 1 = 6-aldehydo-isoophiopogonanone A; 2 = 6-aldehydoisoophiopogonanone $\mathrm{B} ; 3$ = methylophiopogonanone $\mathrm{A} ; 4$ = methylophiopogonanone $\mathrm{B}$

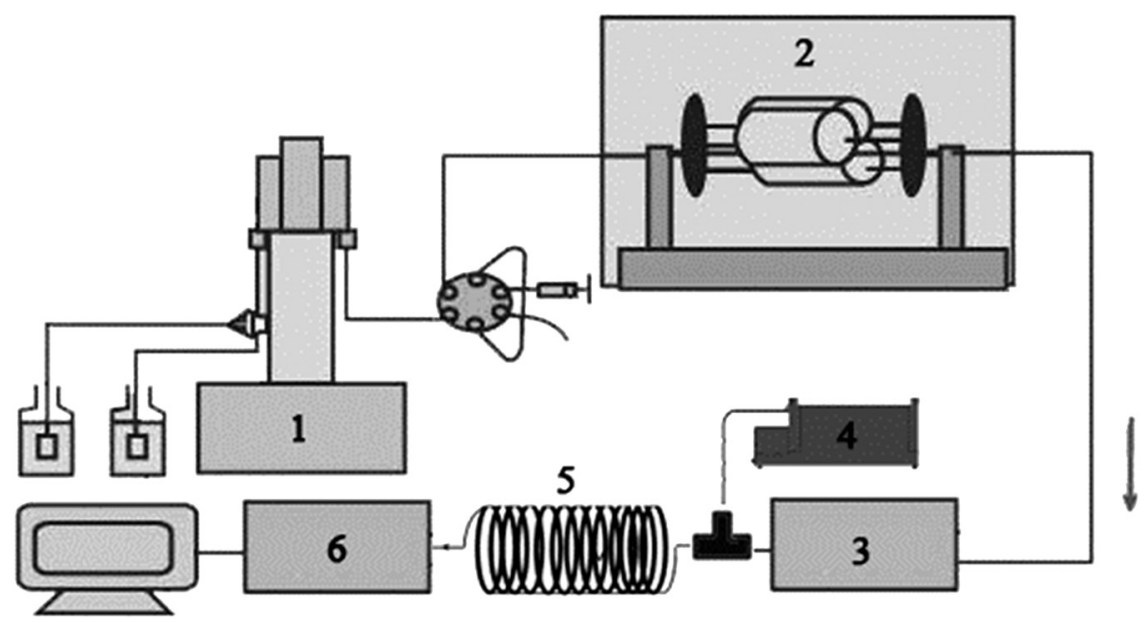

Figure 5. Schematic diagram of the hyphenated HSCCC-DPPH system for online preparative isolation and identification of radical-scavenging compounds: (1) HSCCC pump, (2) HSCCC column, (3) HSCCC detector, (4) DPPH pump, (5) reaction coil, and (6) DPPH detector

DPPH radical scavenging effect of the two compounds were also confirmed, though they had relatively ordinary activity with $\mathrm{IC}_{50}>1000 \mu \mathrm{g} / \mathrm{mL}$.

\section{Conclusion}

The herbaceous plant of $O$. japonicus is well known as a functional food and traditional medicine in China and other 
(A)

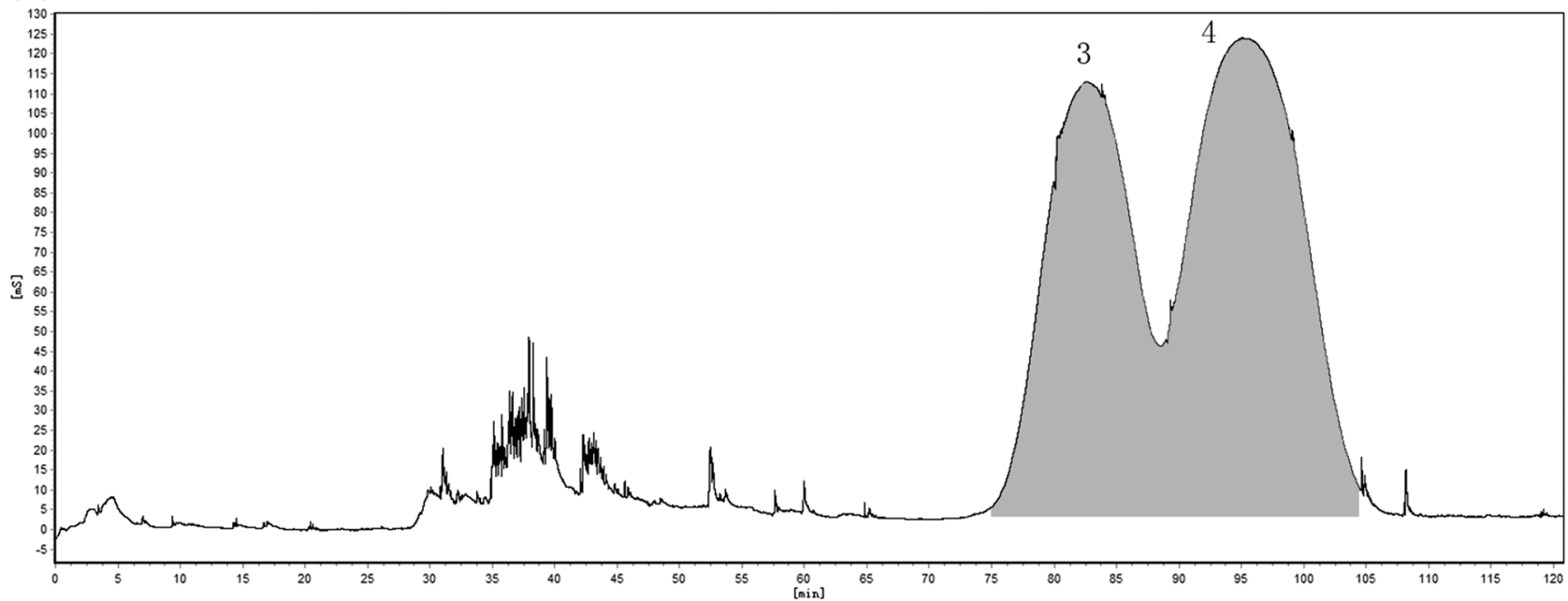

(B)

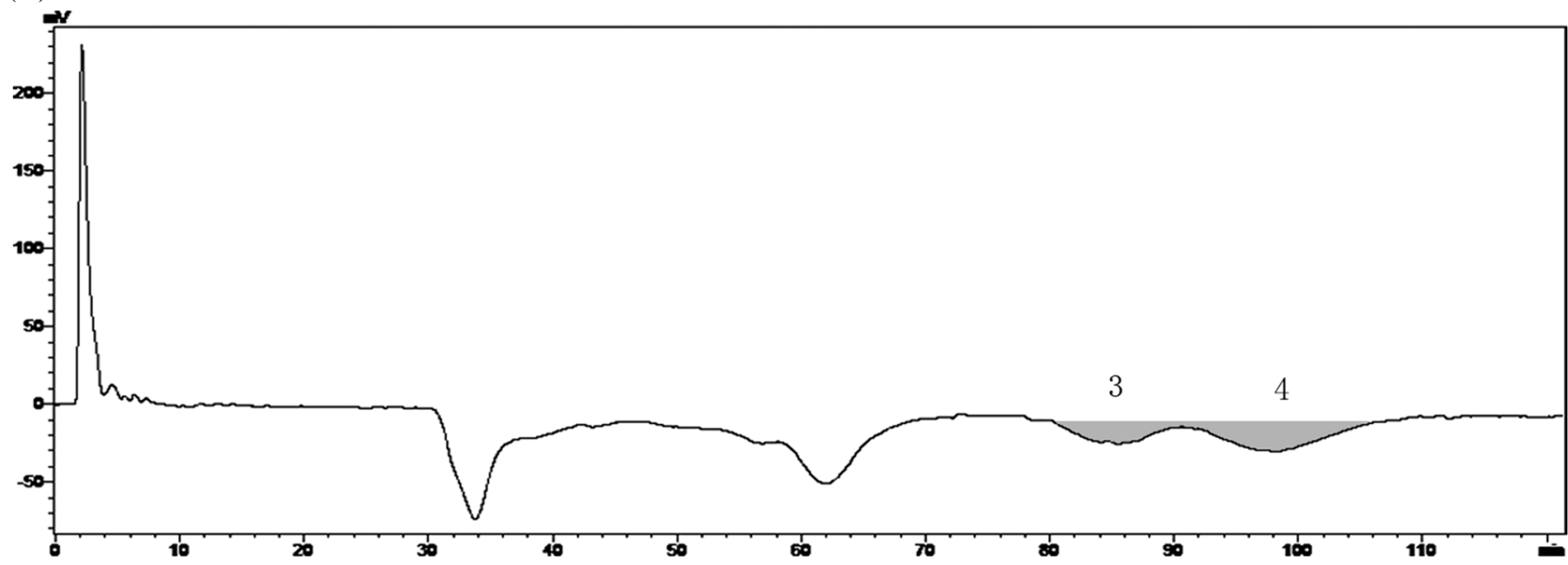

Figure 6. Chromatograms obtained by HSCCC (A) and online DPPH radical scavenging activity (B) from sub-fraction 8 in ethyl acetate extract of FROJ. 3 = methylophiopogonanone A; $4=$ methylophiopogonanone B. HSCCC conditions (A): revolution $=900 \mathrm{rpm}$; flow rate $=2 \mathrm{~mL} / \mathrm{min}$; temperature $=25{ }^{\circ} \mathrm{C}$; detection wavelength $=285 \mathrm{~nm}$; upper phase for stationary phase and lower phase for mobile phase; solvent system: HEAMW $(3: 2: 2.5: 1: 1.5, v / v)$. Online DPPH radical scavenging activity conditions (B): DPPH, $50 \mu \mathrm{mol} / \mathrm{L}$ in methanol; flow rate $=1 \mathrm{~mL} / \mathrm{min}$; detection wavelength, $517 \mathrm{~nm}$

Table 3 The UV and MS data of compounds $1-4$

\begin{tabular}{lccc}
\hline Compounds & $\mathrm{UV} \lambda_{\max }(\mathrm{MeOH})$ & {$[\mathrm{M}-\mathrm{H}]^{-}$} & Formula \\
\hline 1 & 214,274 & 355.0822 & $\mathrm{C}_{19} \mathrm{H}_{16} \mathrm{O}_{7}$ \\
2 & 222,274 & 341.1028 & $\mathrm{C}_{19} \mathrm{H}_{18} \mathrm{O}_{6}$ \\
3 & 216,296 & 341.1045 & $\mathrm{C}_{19} \mathrm{H}_{18} \mathrm{O}_{6}$ \\
4 & 215,297 & 327.1253 & $\mathrm{C}_{19} \mathrm{H}_{20} \mathrm{O}_{5}$ \\
\hline
\end{tabular}

East Asian countries. Previous studies indicated that homoisoflavonoids are main active ingredients, and the FROJ can be the important resource of the plant. In this study, SGCC and rHSCCC was successfully developed to isolate the two pairs of homoisoflavonoid analogues from the FROJ. By the developed method, the fibrous roots could be used to obtain 4 homoisoflavonoids with satisfactory purities, which may then be used for bioactive research or quality control of crude drug or herbal preparations. It is expected to provide meaningful reference for separation and purification of analogues. Furthermore, the online HSCCC-antioxidant activity assay introduced in our experiment will be a useful technique to screening and preparative isolation of antioxidant components from medical plants.

Acknowledgments. This research was supported by Zhejiang Provincial Natural Science Foundation of China (No. LY16C020002), Zhejiang Provincial Science and Technology Project of Analysis Measurement Foundation of China (No. 2014C37071), and National Key Research and Development Program of China (2017YFF0207804, 2016YFF0201904).

\section{References}

1. Zhou, Y. F.; Qi, J.; Zhu, D. N.; Yu, B. Y. Chin. Chem. Lett. 2008, 19 1086-1088.

2. Li, N.; Zhang, J. Y.; Zeng, K. W.; Zhang, L.; Che, Y. Y.; Tu, P. F. Fitoterapia 2012, 83, 1042-1045.

3. Li, N.; Zhang, L.; Zeng, K. W.; Zhou, Y.; Zhang, J. Y.; Che, Y. Y.; Tu, P. F. Steroids 2012, 78, 1-7.

4. Chen, M. H.; Chen, X. J.; Wang, M.; Lin, L. G.; Wang, Y. T. J. Ethnopharmacol. 2016, 181, 193-213.

5. Xi, T.; Liang, Y.; Hao, H. P.; A, J. Y.; Xie, L.; Gong, P.; Dai, C.; Liu, L. S.; Kang, A.; Zheng, X.; Wang, G. J. J Chromatogr A 2012, 1227, 234-244. 6. Zhao, M.; Xu, W. F.; Shen, H. Y.; Shen, P. Q.; Zhang, J.; Wang, D. D.; Xu, H.; Wang, H.; Yan, T. T.; Wang, L.; Hao, H. P.; Wang, G. J.; Cao, L. J. J. Pharmaceut. Biomed. 2017, 138, 134-141.

7. Zhou, Y. F.; Qi, J.; Zhu, D. N.; Yu, B. Y. Chin. J. Nat. Med. 2008, 6, 201-204.

8. Lin, Y. N.; Zhu, D. N.; Qi, J.; Qin, M. J.; Yu, B. Y. J. Pharmaceut. Biomed. 2010, 52, 757-762.

9. Wang, Y. C.; Liu, F.; Liang, Z. S.; Peng, L.; Wang, B. Q.; Yu, J.; Su, Y. Y.; Ma, C. D. Iran J. Pharm. Res. 2017, 16, 357-365.

10. Duan, C. L.; Kang, Z. Y.; Lin, C. R.; Jiang, Y.; Liu, J. X.; Tu, P. F. J. Asian Nat. Prod. Res. 2009, 11, 876-879.

11. Zhou, C. X.; Zou, L.; Mo, J. C.; Wang, X. Y.; Yang, B.; He, Q. J.; Gan, L.; Gan, L. S. Helv. Chim. Acta 2013, 96, 1394-1404.

12. Wang, Y. Y.; Xu, J. Z.; Zhang, L.; Qu, H. B. Helv. Chim. Acta. 2010 93, $980-984$

13. Hung, T. M.; Thu, C. V.; Dat, N. T.; Ryoo, S. W.; Lee, J. H.; Kim, J. C.; Na, M.; Jung, H. J.; Bae, K. H.; Min, B. S. Bioorg. Med. Chem. Lett. 2010, 20, 2412-2416.

14. Zhao, J. W.; Chen, D. S.; Deng, C. S.; Wang, Q.; Zhu, W.; Lin, L. Bmc. Complem. Altern. M. 2017, 17, 7.

15. Gan, L. S.; Zeng, L. W.; Li, X. R.; Zhou, C. X.; Li, J. Bioorg. Med. Chem. Lett. 2017, 27, 1441-1445.

16. He, F.; Xu, B. L.; Chen, C.; Jia, H. J.; Wu, J. X.; Wang, X. C.; Sheng, J. L.; Huang, L.; Cheng, J. Acta Pharmacol. Sin. 2016, 37, 763-771. 
17. Lin, M. B.; Sun, W.; Gong, W.; Zhou, Z. Y.; Ding, Y. S.; Hou, Q. Plos One 2015, 10 .

18. Duan, C. L.; Li, Y. J.; Li, P.; Jiang, Y.; Liu, J. X.; Tu, P. F. Helv. Chim. Acta 2010, 93, 227-232.

19. Duan, C. L.; Ma, X. F.; Jiang, Y.; Liu, J. X.; Tu, P. F. J. Asian Nat. Prod. Res. 2010, 12, 745 .

20. Duan, C. L.; Wang, Y.; Ma, X. F.; Jiang, Y.; Liu, J. X.; Tu, P. F. Chem. Nat. Compd. 2012, 48, 613-615.

21. Kang, Z. Y.; Zhang, M. J.; Wang, J. X.; Liu, J. X.; Duan, C. L.; Yu, D. Q. J. Asian Nat. Prod. Res. 2013, 15, 1230.

22. Lan, S.; Yi, F.; Shuang, L.; Wang, C. J.; Zheng, X. W. Fitoterapia 2013, $85,57-63$.

23. Tian, F.; Shen, L.; Wang, C. J.; Feng, Y.; Zheng, X. W. Chem. Nat. Compd. 2014, 50, 732-734.

24. Qi, J.; Hu, Z. F.; Zhou, Y. F.; Hu, Y. J.; Yu, B. Y. Chem. Pharm. Bull. 2015, 63, 187-194.

25. Li, X. E.; Wang, Y. X.; Sun, P.; Liao, D. Q. J Anal. Methods Chem. 2016, Article ID 7214607.

26. Ito, Y. J. Chromatogr. A 2005, 1065, 145-168.

27. Huang, X. Y.; Di, D. L. TrAC Trend. Anal. Chem. 2015, 67, 128-133.

28. Huang, X. Y.; Ignatova, S.; Hewitson, P.; Di, D. L. TrAC Trend. Anal. Chem. 2016, 77, 214-225.
29. Zhang, P. L.; Xie, N.; Tang, K. W.; Chen, X. M.; Xu, W. F. Sep. Purif. Technol. 2016, 164, 41-48.

30. Grill, C. M. J. Chromatogr. A 1998, 796, 101-113.

31. Du, Q. Z.; Ke, C. Q.; Ito, Y. J. Liq. Chromatogr. Rel. Technol. 1998, $21,157-16$

32. Han, Q. B.; Song, J. Z.; Qiao, C. F.; Wong, L. N.; Xu, H. X J. Chromatogr. A 2006, 1127, 298-301.

33. Xie, J.; Deng, J.; Tan, F.; Su, J. J. Chromatogr. B 2010, 878, 2665-2668. 34. Yang, J. H.; Ye, H. Y.; Lai, H. J.; Li, S. C.; He, S. C.; Zhong, S. J.; Chen, L. J.; Peng, A. H. J. Sep. Sci. 2012, 35, 256-262.

35. Ren, D. B.; Han, B. S.; Xin, Z. Q.; Liu, W. B.; Ma, S. S.; Liang, Y. Z.; Yi, L. Z. Sep. Purif. Technol. 2016, 165, 160-165.

36. Shi, S.; Zhou, H.; Zhang, Y.; Huang, K. Chromatographia 2008, 68 , $173-178$

37. Ma, C. J.; Li, G.; Zhang, J.; Zheng, Q. S.; Fan, X.; Wang, Z. H. J. Sep. Sci. 2009, 32, 1949-1956.

38. Kaneda, N.; Nakanishi, H.; Kuraishi, T.; Katori, T. J. Pharm. Soc. Jap. 1983, 103, 1133-1139.

39. Tada, A.; Kasai, R.; Saitoh, T.; Shoji, J. Chem. Pharm. Bull. 1980, 28, 1477-1484.

40. Watanabe, Y.; Sanada, S.; Ida, Y.; Shoji, J. Chem. Pharm. Bull. 1985, $33,5358-5363$. 